\section{Lung Sounds}

By Paul Forgacs. Pp. 80, illustrated. Baillière Tindall, London, 1978. $£ 4.50$.

This is a difficult book to review because it is not stated for whom the book is intended. This reviewer would certainly not recommend it for undergraduates or those engaged in general medicine or working for the MRCP. Many chest specialists and most academic respiratory physiologists will find it very interesting and stimulating. It probably would be better if the whole of this small book were incorporated in a multiauthor tome on chest disease or respiratory physiology.

\section{Medical Gases. Their Properties and Uses}

By William J. Grant. Pp. 199, illustrated. HM + M

Publishers, Aylesbury, Bucks, 1978. £4.00.

Defining medical gases as those which are inhaled by a patient as directed by his doctor, the author of this book seeks to provide a concise compendium of technical information about them. The potential readership is, as he points out, wide, ranging from Supplies Officers to Pharmacists and clinical users. The book contains a wealth of useful facts, beginning with general chapters on the physical chemistry, handling and storage of gases and going on to more detailed ones on the individual agents, including volatile liquids. Small criticisms may be made of the second section; any medicallyqualified reader, for instance, would be surprised to read that loss of consciousness can be induced by nitrous oxide in a concentration of as little as $35 \%$, or that concentrations greater than $80 \%$ can be administered without causing hypoxia. A more considerable limitation on the book's value, however, is its failure to include, at the end of each chapter, a list of further reading. There is a short list of references at the end of the book, but this is by no means comprehensive. If these omissions could be rectified in a second edition, this book would become really useful.

Mycotoxic Fungi, Mycotoxins, Mycotoxicoses. An Encyclopedic Handbook. Volume 1. Mycotoxic Fungi and Chemistry of Mycotoxins.

Edited by T. D. Wyllie and L. G. Morehouse. Pp. 538, illustrated. Marcel Dekker, New York and Basel, 1977. SFr. 230. (Set of 3 vols $\$ 156.00$ ).

It is less than two decades since the discovery of aflatoxin heralded the modern era of mycotoxicology. The rate at which new information is accumulating is high and has shown no signs of a decline. Several new texts have appeared in the literature in the past decade. This new three-volume handbook is an ambitious and much needed treatise, which attempts the formidable task of summarizing current knowledge on mycotoxic fungi, mycotoxins and mycotoxicoses. For this purpose, the assistance of 46 authors from 11 countries has been enlisted. The first volume deals with mycotoxic fungi and the chemistry of mycotoxins. It contains 21 contributions from 7 countries - a measure of the international nature of the subject. It contains a wealth of information, and more than 2000 references are to be found within its covers. The text has a curious and initially confusing numerical system of subdivision for the individual sections. Once mastered, however, the convention is not obtrusive and there is certainly no diifficulty in locating individual topics. With any multiauthor volume, it has to be expected that there will be uneven treatment of the different chapters, and this first part is no exception. Contributions are written by recognized authorities and the quality of presentation is both high and sustained.

Keys are freely used. The rationale for their inclusion is to some extent obscure, but they may be of value in identifying species which are of known or suspected toxigenicity.
The quality of illustrations and tabular material chosen is generally very high, with only occasional lapses. In the chapter dealing with the genus Fusarium, for example, there has been a reasonable compromise made between different taxonomic systems but arithmetic errors have been made in the statistical summaries provided for spore sizes.

The physical appearance of the volume is frankly disappointing. This is a quality publication, but in content rather than appearance. The text is clear but functionally adequate rather than attractive. The covers are aesthetically unappealing and the binding is by no means robust.

Nevertheless, there is no gainsaying the quality of individual contributions, and if subsequent volumes match the standards set by this first volume, the scientific community will be substantially enriched by this well devised, well edited and informative text book, which will set the standard for years to come.

\section{Research in Medicine. Problems and Prospects.}

By Sir Andrew Watt KaY. Pp. 122+xiii, hard cover. The Nuffield Provincial Hospitals Trust, London, 1977. $£ 3.50$.

The Rock Carling Fellowship was founded as an annual memorial to the late Sir Ernest Rock Carling, Chairman of the Nuffield Trust Medical Advisory Committee. Each holder of the Fellowship reviews, in a public lecture and monograph, the state of knowledge in a Rock Carling field of interest. Sir Andrew' Watt Kay was given the formidable task of peering ahead to determine the future of medical research. This is a beautifully written essay of the way academic medicine is pressing forward, and also how it is being held back by the new scheme of overtime payments to junior hospital doctors. It is the author's fervent, but perhaps futile hope that we can return to paying hospital doctors in our National Health Service a salary for the job and that the salary will be compatible with that received by our colleagues in other countries. There is a fascinating chapter on future trends in medical research, in which he throws out suggestions for many an M.D. thesis.

This monograph is for the serious minded academic in medicine, but it is strongly recommended to the overseas postgraduate who intends to return to his own country in order to plan its future health services. This book provides guidelines for a healthy growth of those services.

He closes with Shakespearian hopes for the third world: 'Our children's children shall see this, and bless heaven'. (Henry VIII, Act V, Scene V.)

\section{Side Effects of Drugs Annual 2. A Worldwide Yearly Survey} of New Data and Trends.

Edited by M. N. G. Dukes. Pp. 450. Excerpta Medica, Amsterdam, Oxford, 1978. \$44.95.

The importance of adverse drug reactions to the prescribing doctor is increasing rapidly for many reasons, not least being concern for the best patient care. In many therapeutic areas, doctors have a choice of appropriate preparations of similar efficacy, and in such a situation safety and acceptability become of great importance in decision making. Growing awareness of the need for information on adverse drug reactions has led to publication of large numbers of reports of such reactions of varying scientific standards in a multitude of clinical journals, both national and international, most of which are inaccessible to the majority of doctors. The Side Effects of Drugs Annual, published in January of each year, provides a detailed, critical, yet concise account of new information on adverse reactions, and this second volume reviews all reports presenting such information from August 1 st 1976 to July 31 st 1977 . It is well produced and, although expensive, will be invaluable as a ready source of reference to the prescribing doctor or hospital drug information officer. 